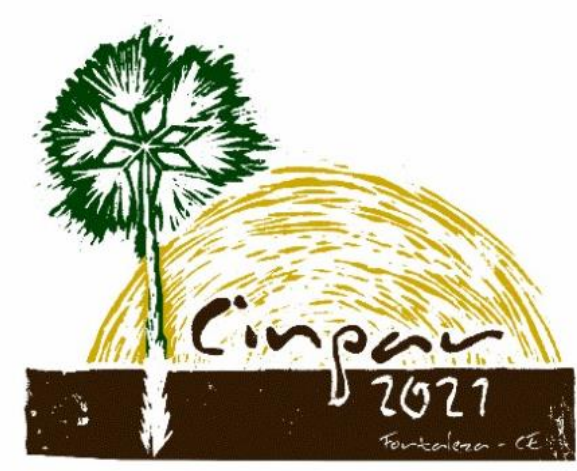

XVII Congresso Internacional sobre Patologia e Reabilitação das Construções

XVII Congreso Internacional sobre Patología y Rehabilitación de las Construcciones

XVII International Conference on Pathology and Constructions Rehabilitation

FORTALEZA (Brasil), 3 a 5 de junho de 2021

https://doi.org/10.4322/CINPAR.2021.004

\title{
Avaliação das manifestações patológicas de um edifício na cidade Juazeiro do Norte, Ceará.
}

\section{Evaluation of the pathological manifestations of a building in the city of Juazeiro do Norte, Ceará.}

Camile Pereira ${ }^{(1)}$, Taísa Felix Brito ${ }^{(2)}$, Cicera Adailza Mourão da silva ${ }^{(3)}$, Miguel Adriano Gonçalves Cirino ${ }^{(4)}$ Bruno Barbosa de Oliveira ${ }^{(5)}$,Samuel Bezerra Cordeiro ${ }^{(6)}$

${ }^{1}$ Universidade Regional do Cariri, Brasil.camiperi1991@outlook. Universidade Regional do Cariri, Brasil.taisafelix07@gmail.com ${ }^{3}$ Universidade Regional do Cariri, Brasil, adaiza_mourao@hotmail.com

${ }^{4}$ Universidade Regional do Cariri, Brasil.miguel.goncalves@urca.br

${ }^{5}$ Universidade Regional do Cariri, Brasil, bruno.barbosa@urca.br

${ }^{6}$ Universidade Regional do Cariri, Brasil. samuel.cordeiro@urca.br

Resumo: $O$ presente estudo visa a avaliação das maninestações patológicas observadas em uma antiga concessionária de veículos, localizada no município de Juazeiro do Norte - Ceará. Assim, buscou-se analisar o estado de conservação da edificação com ênfase na possibilidade de reforma e recuperação, procurando identificar as principais manifestações patologias e determinar possíveis soluções para as mesmas. No processo de avaliação foram feitas inspeções visuais, análises táteis e entrevistas com moradores das vizinhanças. Na sequência, determinou-se as possíveis causas e a possibilidade de reparos, por meio de comparação com dados bibliográficos. Os resultados apontam que as principais manifestações patológicas observadas são infiltrações, desplacamento do revestimento, recalque do solo, corrosão de armaduras, manchas e deterioração proveniente de ações humanas como depredações e falta de manutenção. As condições observadas indicam risco à saúde e segurança de moradores que por ali circulam, relacionada também com os altos custos de recuperação dos diversos ambientes da edificação.

Palavras-chave: Manifestação patológica, Inspeção predial, Estado de conservação.

Abstract: The present study aims to evaluate the pathological manifestations observed in an old car dealership, located in the municipality of Juazeiro do Norte - Ceará. Thus, we sought to analyze the state of conservation of the building with an emphasis on the possibility of renovation and restoration of the building, seeking to identify the main pathological manifestations and determine possible solutions for them. In the evaluation process, visual inspections, tactile analyzes and interviews with residents of the neighborhood were carried out. Then, the possible causes and the possibility of repairs were determined, through comparison with bibliographic data. The results show that the main pathological manifestations observed are infiltrations, peeling of the lining, repression of the soil, corrosion of armor, stains and deterioration resulting from human actions such as depredation and lack of maintenance. The observed conditions indicate a risk to the health and safety of residents who circulate there, also related to the high costs of recovery of the different building environments.

Keywords: Pathological manifestation, Building inspection, State of conservation.

\section{Introdução}

As manifestações patologias em edificações comprometem a habitabilidade, a vida útil da edificação, a estética e a funcionalidade dos diferentes sistemas. Muitos dos problemas decorrem de falhas no processo de execução, no planejamento e gestão da construção, ausência de detalhamento dos projetos, bem como 
das escolhas e especificações dos materiais de construção e componentes, ações atmosféricas (variações de umidade, temperatura) e também decorrente do uso da edificação (PACHECO, 2013 e HELENE, 1993).

$\mathrm{Na}$ busca de reduzir a incidência de manifestações patológicas as edificações devem ser projetadas atendendo as normas técnicas e executadas com as melhores práticas para se garantir que se alcance a vida útil de projeto (VUP), não obstante à necessidade de avaliação das condições da edificação e associada à manutenção preventiva, que auxiliam no aumento da vida útil da edificação, e resultam em menores desembolsos financeiros para a correção de eventuais manifestações patológicas (VILLANUEVA, 2015).

Em edificações comerciais, destaca-se o uso de tecnologias construtivas voltadas para uso de elementos esbeltos (Concreto armado ou estruturas metálicas), o uso de arquitetura arrojada ou funcional, com uso de materiais duráveis e de fácil manutenção. No entanto, quando as condições de manutenção ou de avaliação da edificação são negligenciadas, as edificações passam por um processo de degradação, muito associado às condições de uso e atmosféricas na qual se localizam. O agravamento destas condições é observada em situações de abandono, onde evidenciam-se processos acelerados de deterioração e, em muitos casos as edificações são depredadas e vandalizadas, transformando este ambiente em um local de risco para transeuntes e edificações vizinhas.

O trabalho em questão visa identificar, determinação de causas prováveis e proposição de ações corretivas para as principais manifestações patológicas observadas em uma concessionária de veículos abandonada, localizada na cidade de Juazeiro do Norte - Ceará.

\section{Materiais e métodos}

A edificação analisada, trata-se de uma antiga concessionária de veículos, localizada na Avenida Padre Cícero, $s / n$, bairro Triângulo, no município de Juazeiro do Norte - CE, nas proximidades de universidades, hospitais, centros de comercio e vias de intensa movimentação de veículos e pedestres. A edificação é composta por um prédio principal com dois pavimentos, dois anexos e um reservatório de água onde, atualmente, o edifício encontra-se abandonado (a cerca de uma década). A Figura 1 apresenta a vista da fachada principal do edifício.

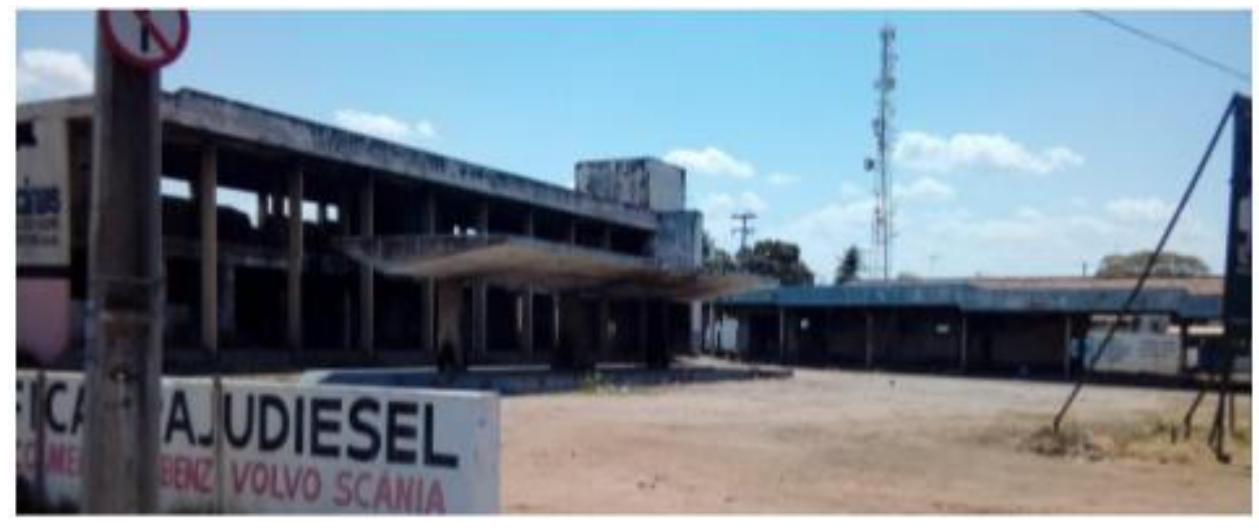

Figura 1 - Vista frontal da edificação

Forma feitas duas visitas técnicas à edificação, entre o dia 16 de maio e 21 de junho de 2020. Inicialmente, buscou-se fazer uma análise preliminar das manifestações patológicas, observar o estado de conservação da edificação e elaboração de um croqui da disposição do layout dos setores (Figura 2), tendo em vista a ausência de projetos. A segunda visita foi realizada com o objetivo de se fazer uma análise mais aprofundada das manifestações observadas com registro fotográfico, identificação do estado de conservação da edificação em função dos ambientes. 
Assim, buscou-se aferir as espessuras das fissuras com uso de trena milimetrada, anotando-se as espessuras médias observadas, além de análise tátil do solo e dos revestimentos argamassados dos ambientes, anotando no croqui as informações obtidas e o estado de conservação.

Concluídas as visitas técnicas, iniciou-se o estudo bibliográfico comparativo, além da identificação das causas mais prováveis das manifestações patológicas e indicações de reparos.

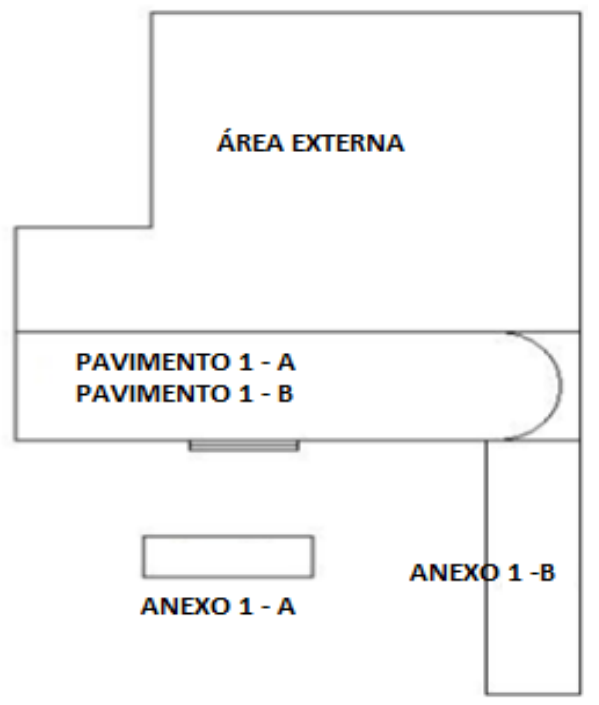

Figura 2 - Croqui da edificação (concessionária desativada)

\section{Resultados e Discussão}

\subsection{Anexo $1 \mathrm{~A}$, Anexo $1 \mathrm{~B}$ e Pátio de entrada da concessionária}

Na entrada principal e nos anexos $1 \mathrm{~A}$ e $1 \mathrm{~B}$, foram verificadas a degradação dos elementos de vedação, acúmulo de águas pluviais. Na parte superior do pórtico não foi verificado sistema de impermeabilização; porém percebeu-se a obstrução das instalações de escoamento pluvial. Esta situação possibilita o acúmulo de água, podendo causar a proliferação de vetores de doenças, bem como a ocorrência de eflorescências e manchas por umidade, conforme observado nas Figuras 3 e 4.

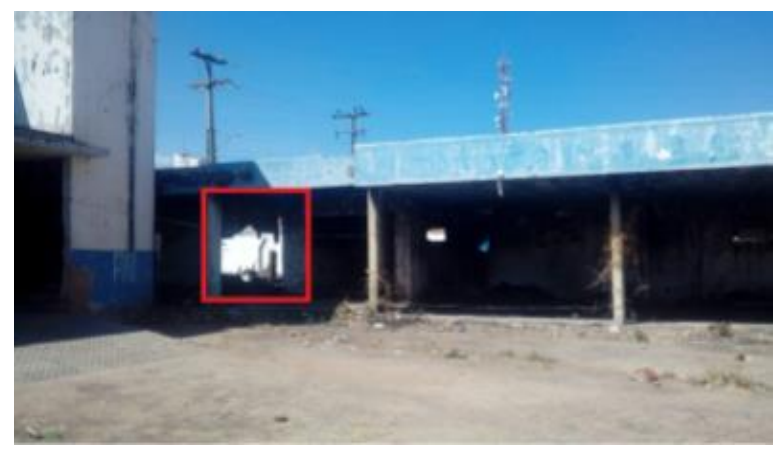

Figura 3 - Anexo 1B (exposição de veículos)

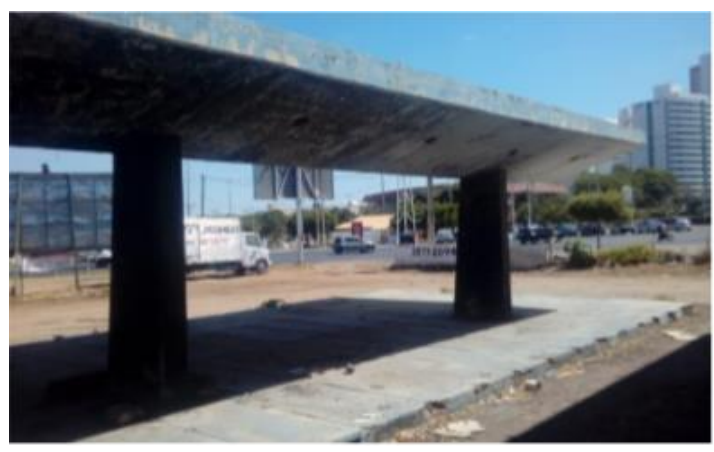

Figura 4 - Anexo 1 A (recepção)

Na parte inferior do elemento de laje, Anexo 1 A (Figura 5), observam-se a formação de depósitos cristalinos de cor branca sobre o concreto (eflorescências), decorrente da percolação da água pelo concreto e carreando os sais solúveis e manchas de umidade (VITÓRIO, 2003). Pode-se verificar também que, em alguns locais o concreto já se encontra desagregado, devido a ocorrência de corrosão das armaduras. 
Apontam-se como fatores principais a ausência de impermeabilização e a manutenção. Também foi verificada a carbonatação do concreto, fato condizente com a localização da edificação às margens de vias de alto fluxo de veículos. Sugere-se uma investigação mais aprofundada da estabilidade do pórtico como um todo, mesmo não se verificando fissuras nos pilares.

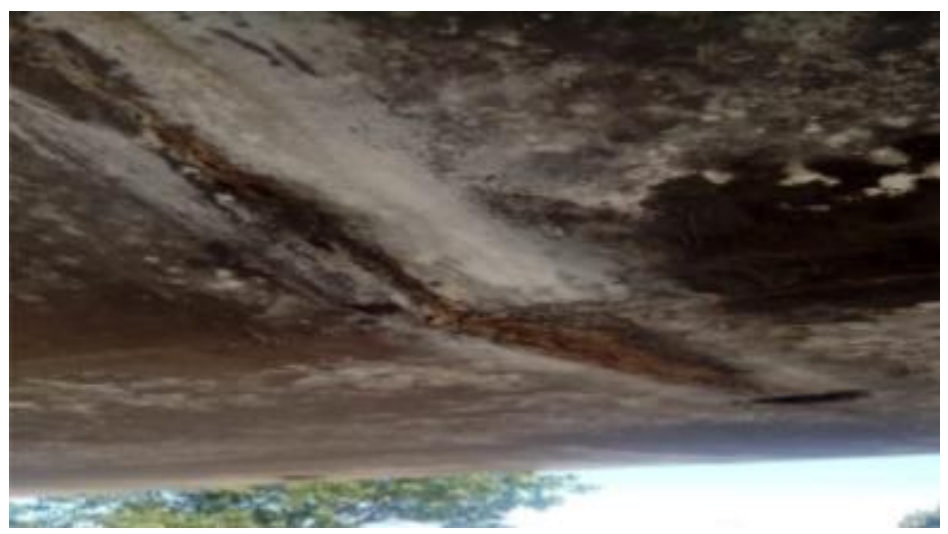

Figura 5 - Parte inferior da laje da recepção (Anexo 1 A)

No antigo local utilizado para a exposição dos veículos (pátio de vendas), foi verificado o desplacamento do concreto na parte inferior da laje, bem como a incidência de corrosão das armaduras e manchas de umidade e de poluição espalhadas nas alvenarias, teto e piso (Figura 6).

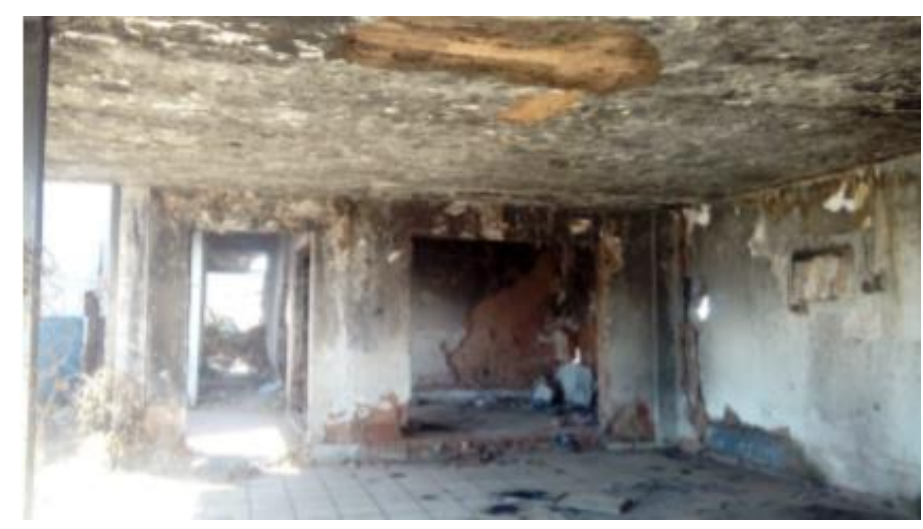

Figura 6 - Área interna do Anexo 1B

Estas manifestações patológicas associam-se à ausência de manutenção e infiltrações proveniente do pavimento superior, além da depredação recorrente por toda a edificação. A situação apresentada põe em risco à saúde e segurança de eventuais usuários da edificação, uma vez que há indícios de corrosão generalização por toda a extensão da laje, além de desplacamento de elementos de vedação do forro e do concreto de recobrimento da laje.

Para os elementos de vedação (paredes), as Figuras 7 e 8 , respectivamente, área externa e interna, apresentam descolamento da argamassa de revestimento, em sua maior parte, com manchas de umidade, provocando o aparecimento de bolor, formação de eflorescência, vesículas na superfície da tinta e fissuras com abertura média entre $1,0 \mathrm{~mm}$ a 2,0 $\mathrm{mm}$ e de conformações variadas que se estende do teto ao longo de toda parede. O bolor é uma alteração observável na superfície de diferentes materiais, sendo uma consequência do desenvolvimento de microrganismos pertencentes ao grupo dos fungos que se depositam na superfície do material, necessitando de ambiente com umidade (SOUZA, 1998). Nas edificações promovem a decomposição de diferentes tipos de componentes, notadamente revestimentos ou de material orgânico sobre estes depositados. 
As condições ambientais afetam o desenvolvimento de fungos e bolor, sobretudo na ocorrência de umidade, umidade relativa do ar, ventilação do ambiente, altas temperaturas, entre $10^{\circ}$ e $35^{\circ} \mathrm{C}$, comum na região onde se encontra a edificação e o tipo de substrato (SOUZA, 1998).

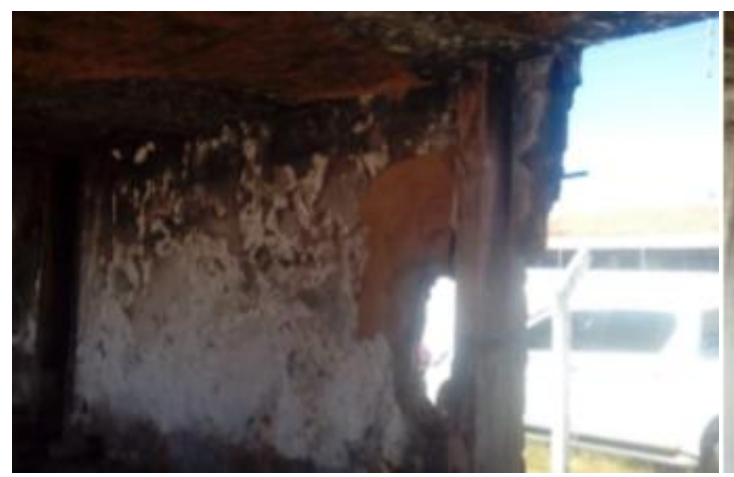

Figura 7 - Parede externa do Anexo 1B

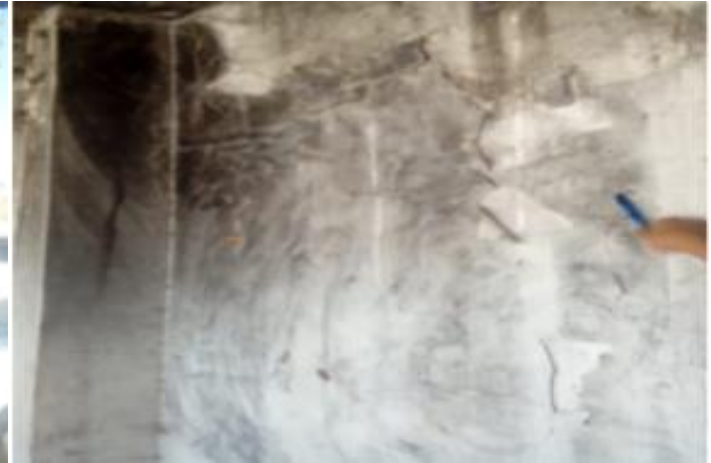

Figura 8 - Parede interna Anexo 1B

O vandalismo e depredação da edificação também fica evidente na Figura 9, onde a alvenaria foi parcialmente destruída para a retirada dos elementos da instalação elétrica, como eletrodutos e condutores. No mesmo ambiente, foi possível observar que a superfície do revestimento apresenta descolamento do piso cerâmico da camada de aderência, conforme Figuras 9 e 10. No geral, o piso encontrava-se com pouco fragmentos de piso cerâmico e com desagregação do contrapiso. Por inspeção tátil, o material utilizado com contrapiso não se fragmentava e não foi observado recalques ou expansão do piso.

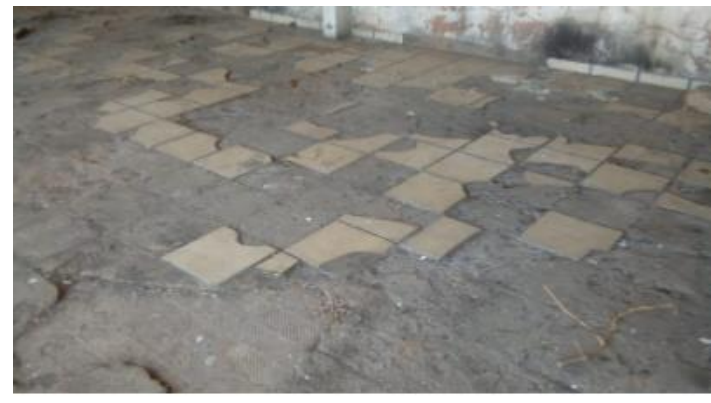

Figura 9 - Piso Anexo 1B

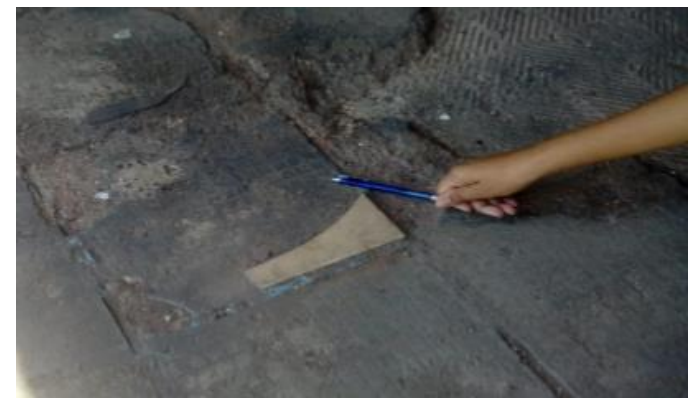

Figura 10 - Piso Anexo 1B

Devido as condições observadas, indicam-se como causas prováveis decorrem de vandalismo, ausência de manutenção, umidade advinda da falta de impermeabilização e desgaste natural dos materiais utilizados. Estas condições causam prejuízo estético e baixo risco aos indivíduos que circulam nas proximidades desta área da edificação.

Para os anexos 1A e 1B, a habitabilidade ou correções podem se tornar inviáveis, em decorrência do grau de comprometimento dos componentes da edificação e do grau de acometimento deles, com destaque para o processo de corrosão, condições das alvenarias e revestimentos.

\subsection{Edificação principal, Pavimento 1A (térreo) e 1B (piso superior)}

Na parte interna da edificação, no pavimento térreo, observam-se indícios de um incêndio, em decorrência das manchas de foligem e deterioração do revestimento, conforme observado na Figura 13.

Não é possível determinar quando ocorreu este incêndio, no entanto, acredita-se que ocorreu de forma intencional, provavelmente induzido por pessoas que utilizam este local para consumo de entorpecentes. Esta situação tende a agravar as condições gerais da edificação prejudicando ou aumentando os custos de possíveis reparos do edifício, necessitando de uma investigação da estabilidade geral do prédio principal. 


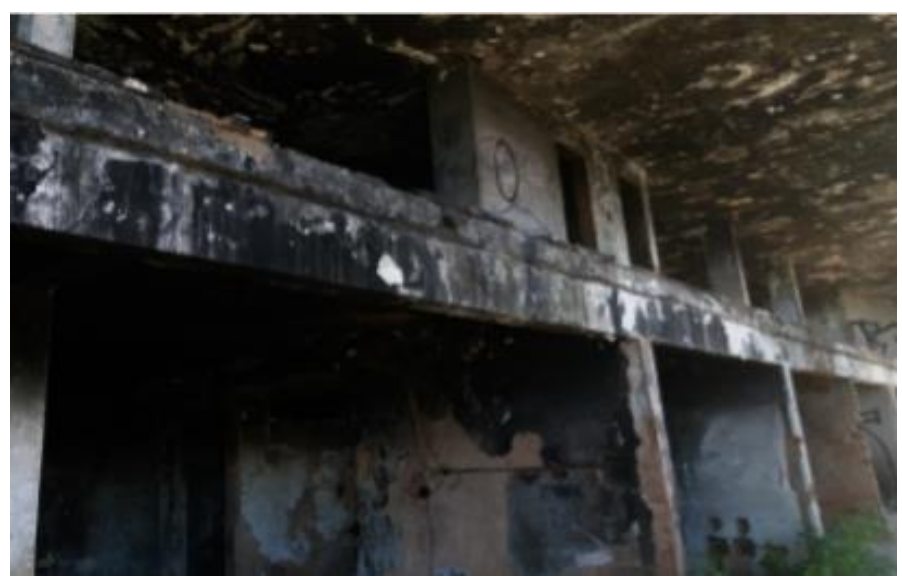

Figura 13 - Pavimento 1A e 1B (indício de incêndio)

Nas paredes internas dos Pavimentos $1 \mathrm{~A}$ e 1B, observa-se fissuras, além da desagregação da pintura e do revestimento das paredes. (Figura 14).

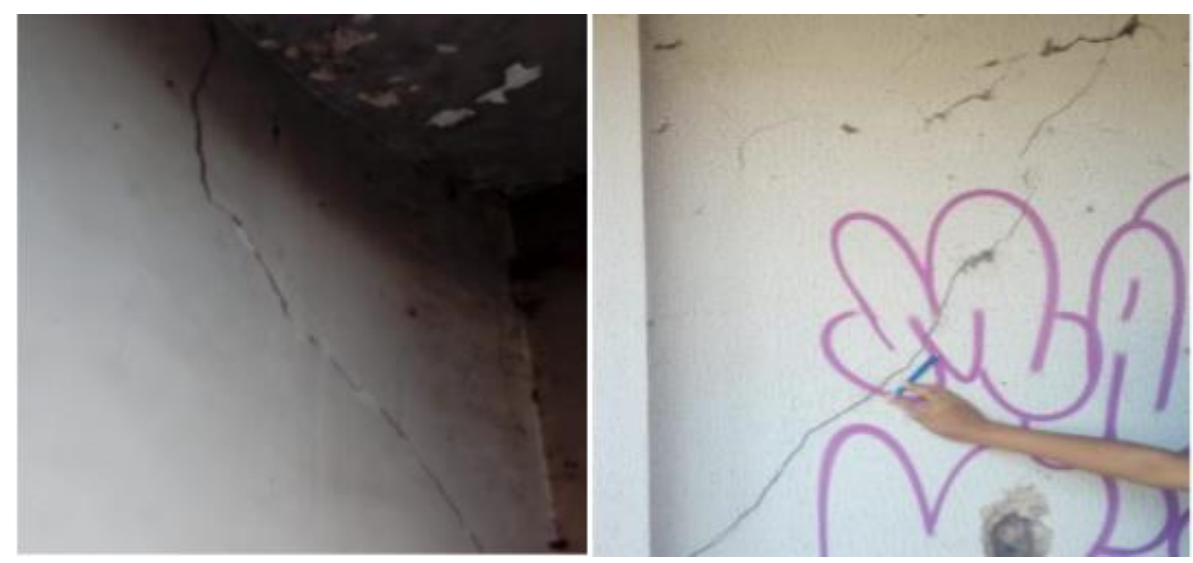

Figura 14 - Alvenarias internas dos Pavimentos $1 \mathrm{~A}$ e $1 \mathrm{~B}$

A ocorrência de fissuras foi verificada em todas as alvenarias internas da edificação, com morfologia variada, abertura média variando entre $2,0 \mathrm{~mm}$ e $8,0 \mathrm{~mm}$, aferidas com uso de régua milimetrada, e com destaque para fissuras inclinadas em $45^{\circ}$ e extensão do teto ao piso. As fissuras, foram as observadas nos elemento da estrutura da edificação, tais como pilares, vigas e lajes.

Estas ocorrências indicam possíveis problemas estruturais decorrentes de deformações, recalque do solo (indicação menos provável de ocorrer nesta edificação, uma vez que não se constatou o recalque do solo) e ocorrência de corrosão dos elementos estruturais. Nesta ocasião, sugere-se uma melhor avaliação das condições estruturais. Na Figura 15 verifica-se fissuras, com abertura superior a 1,0cm, entre o elemento de vedação (parede) e os elementos estruturais (pilar e viga). Para estas fissuras, não se observou alteração Acredita-se que o travamento da alvenaria nos elementos estruturais viga e pilar não foi executado de maneira ideal, uma vez que não se observou junta na abertura, além de uma maior abertura na parte superior da alvenaria, podendo indicar deformação do pilar. 

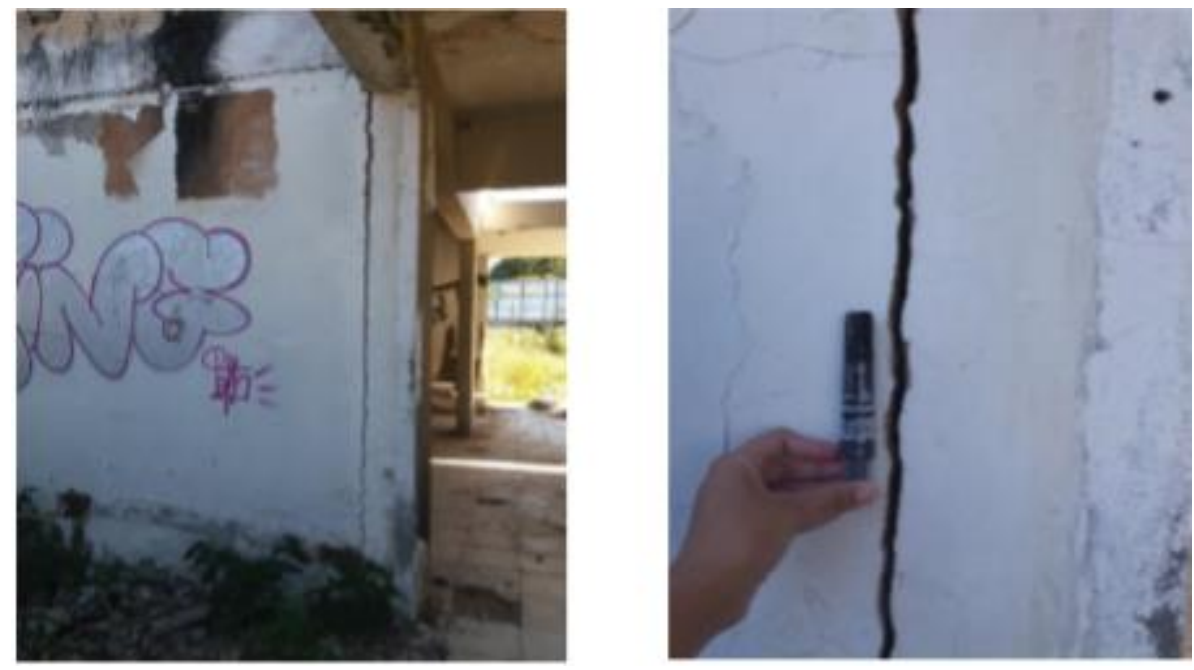

Figura 15 - Alvenaria externa ao Pavimento $1 \mathrm{~A}$

Nas dependências dos Pavimentos 1A e 1B se observam processos corrosivos, deplacamento e desagregação do concreto e ocorrência de manchas e eflorescências, sobretudo no pavimento superior. As Figuras 16, 17, 18 e 19 apresentam as condições observadas nas lajes dos Pavimentos 1A e $1 B$.

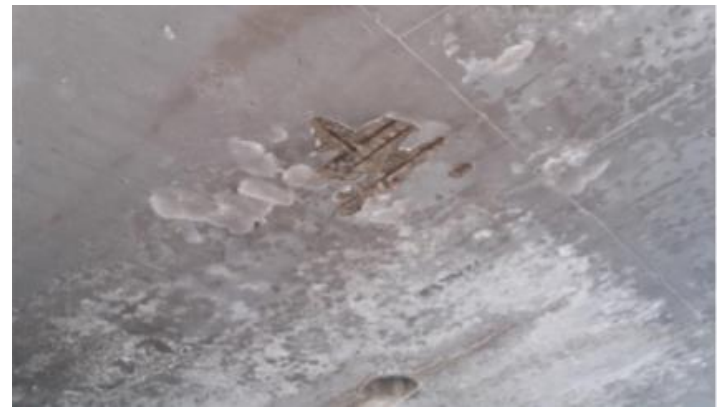

Figura 16 - Laje Pavimento $1 \mathrm{~A}$

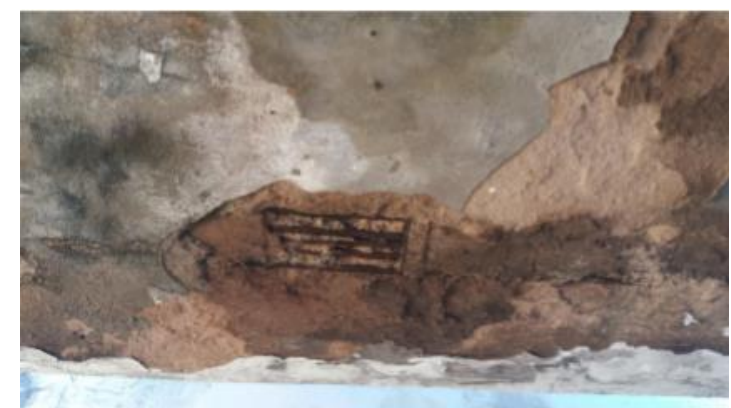

Figura 17 - Laje Pavimento $1 \mathrm{~B}$

Nas Figuras 16 e 17 observa-se a ocorrência de corrosão das armaduras inferiores das lajes e desplacamento do concreto de recobrimento destes elementos estruturais. Nas Figuras 18 e 19 percebe-se a ocorrência de manchas de umidade, formação de bolor e desagregação de parte do concreto.

Destaca-se a ausência de impermeabilização, a possível carbonatação do concreto como principais causadores destas manifestações patológicas. Em virtude das ocorrências observadas e do alto grau de comprometimento da edificação, quanto aos elementos estruturais, indicam a necessidade de restrição de acesso ao edifício e buscar análises mais aprofundadas dos elementos estruturais.

A vista geral do Pavimento $1 \mathrm{~A}$ (térreo), Figura 20, apresenta o estado de conservação da edificação como um todo, com destaque para as manchas de umidade e formação de bolor, na parte superior (teto). Percebe-se também o desplacamento do concreto e, no pilar central (centro da imagem), verifica-se um dano proveniente da tentativa de retirar a tubulação da instalação elétrica.

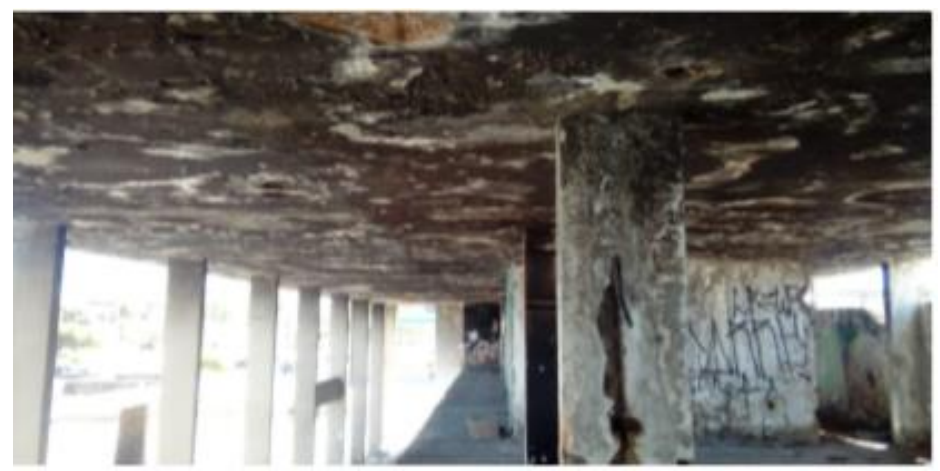

Figura 20 - Vista geral do Pavimento $1 \mathrm{~A}$ 
Em termos gerais, observam-se fissuras, corrosão, desagregação de elementos de concreto, perda de elementos de vedação e revestimento das paredes e do piso, ausência de impermeabilização e depredação geral da edificação. Estas ações decorrem do abandono da edificação, da ausência de manutenção e da não limitação de acesso ao local o pode pôr em risco eventuais usuários da edificação.

\section{Conclusões}

Ao avaliar as manifestações patologias encontradas na edificação, conclui-se que o edifício apresenta problemas decorrentes de fatores humanos, em decorrência do estado de abandono que se encontra atualmente, sobretudo por incidentes como indicativo de incêndio, além de depredação de elementos de vedação. Além de fatores externos relacionados ao ambiente onde a edificação se encontra, em via de alto tráfego de veículos, relacionados à carbonatação do concreto e corrosão das armaduras.

As manifestações patológicas observadas, tais como as fissuras, o desplacamento de estruturas de concreto, além de processos corrosivos, a perda de integridade dos revestimentos e manchas de eflorescência; poluição e umidade; tendem à causar além de depreciação estética da edificação e de áreas vizinhas, também indicam uma redução da capacidade portante das estruturas, causando risco à integridade física e a saúde de eventuais usuários da edificação.

Quanto ao enquadramento das anomalias e falhas presentes são considerados de difícil correção, uma vez que se apresentam-se em toda a edificação, associada à falta de manutenção preventiva e abandono, podem indicar altos custos para reparo e recuperação dos sistemas estruturais, revestimentos, drenagem e impermeabilização da edificação.

Assim, estudos práticos que visem a avaliação do estado de conservação de edificações, reforçam a importância dos planos de manutenção e a necessidade de monitoramento destes ambientes, evitando-se altos custos para recuperação da edificação. Evitando-se que a edificação seja abandonada tornando-se ponto de insegurança para a comunidade e, com risco para transeuntes ou eventuais usuários do espaço.

\section{Referências Bibliográficas}

ASSOCIAÇÃO BRASILEIRA DE NORMAS TÉCNICAS. NBR15575-1:2013 - Edificações habitacionais Desempenho parte 1: Requisitos gerais. Rio de Janeiro, Brasil.

COSTA, Vitor Coutinho de Camargo. Patologia em edificações com ênfase em estruturas de concreto. 2009. $38 \mathrm{f}$. Trabalho de Conclusão de Curso, Universidade Anhembi Morumbi, São Paulo, 2009. Dispo nível em: <http://www.academia.edu/31785497/PRINCIPAIS_PATOLOGIAS_NA_CONSTRU\%C 3\%87\%C3\%830_CIVIL>. Acesso em: 20 de abril de 2019.

HELENE, P. R. L. Contribuição ao estudo da corrosão em armaduras de concreto armado. 1993. 231p. Tese (Livre Docência) - Universidade de São Paulo. São Paulo, 1993

MENEGATTI J.B. Fissuras em fachadas: análise e incidência em edificios na Cidade de ChapecósC. Monografia. Unochapecó, Chapecó, 2008

PACHECO, J.; HELENE, P.; ENGENHARIA, P. Entenda o Concreto: Controle da resistência do concreto - 2a Parte. Revista Ibracon, Gramado, 2013. 90-98. 55을 Congresso Brasileito de Concreto.

REIS, W. P. da S. (2013). Revestimento cerâmico de fachada: projeto do produto e da produção. 2013. 99 f. Trabalho de Conclusão de Curso (Graduação em Engenharia Civil). Coordenação de Construção Civil, Universidade Tecnológica Federal do Paraná, Campo Mourão

SOUZA, Vicente Custódio Moreira de; RIPPER, Thomaz. Patologia, recuperação e reforço de estruturas de concreto. São Paulo: PINI, 1998.

VILLANUEVA, M.M. A importância as manutenção preventiva para o bom desempenho da edificação. 144 p. Projeto de Graduação UFRJ. Departamento de Construção Civil, Escola Politécnica da Universidade Federal do Rio de Janeiro, 2015.

VITÓRIO, A. Fundamentos das Patologias das Estruturas nas Perícias de Engenharia. Recife, 2003. 
Avalaição das manifestações patológicas em un edifício na cidade de juazeiro do Norte - CE 